\title{
Aquele que recebeu em paga: acerca de um Camões no poema de Sophia
}

Virginia Boechat

(Universidade de São Paulo)

\section{RESUMO}

O presente ensaio propõe-se a desenvolver uma leitura do poema "Camões e a tença", de Sophia de Mello Breyner Andresen, na busca de compreender criticamente a imagem ali constituída do poeta Luís de Camões.

PALAVRAS-CHAVE: Sophia de Mello Breyner Andresen, Camões, Literatura e valor.

\begin{abstract}
This essay intends to read the Sophia de Mello Breyner Andresen's poem "Camões e a tença". Therefore, it aims at understanding the image of Luís de Camões as presented in that poetic text.
\end{abstract}

KEYWORDS: Sophia de Mello Breyner Andresen, Camões, Literature and value. 
Nunca choraremos bastante nem com pranto

Assaz amargo e forte

Aquele que fundou glória e grandeza

E recebeu em paga insulto e morte

Sophia de M. B. Andresen, "Pranto pelo

Infante D. Pedro das Sete Partidas"

"Irás ao Paço. Irás pedir que a tença/ Seja paga na data combinada", assim começa o poema de Sophia de Mello Breyner Andresen intitulado "Camões e a tença", do volume Dual (1972), provavelmente um dos textos mais conhecidos do conjunto de sua obra poética. O título, que relaciona o poeta a essa pensão e sua simbólica ida ao palácio real para pedir pontualidade ou continuidade no pagamento, logo de início, indica que os versos têm como assunto a reles recompensa oferecida àquele que escreveu o livro de fundação nacional. Aparentemente, dois vetores principais contribuem para construção de uma imagem humilhada de Camões nos versos: por um lado, de forma mais explícita, o necessário ato de irpedir, numa espécie de mendicância mais refinada; por outro, pouco mais sutil, alguma ofensa contida numa noção de remuneração dada a ele pelo governo, que histórica e ficcionalmente foi quase sempre tida como escassa. Por isso, "Irás ao Paço irás pacientemente/ Pois não te pedem canto mas paciência" (ANDRESEN, 2004, p. 72), complementa o poema andreseniano.

Muito já se discutiu se essa tença tinha origem na sua atividade de poeta ou de soldado, ou em ambas; muito se ponderou a real quantia, assim como quem a ia buscar ao palácio. Na edição d'Os Lusíadas organizada por Emanuel Paulo Ramos, por exemplo, na parte que se ocupa da "Vida de Luís de Camões", a nota de número trinta e quatro faz um levantamento das opiniões de estudiosos camonianos acerca daquele prêmio, do valor e da sua insignificância ou não; há quem calcule que era exígua e até quem acredite que era uma larga quantia (cf. RAMOS, in CAMÕES, 2003, p. 37). Mas esse assunto quantitativo não é o que movimenta esta reflexão, quando muito apenas indiretamente.

Também poderíamos circular de maneira crítica pelas imagens de Camões que desde o século XVII vêm sendo construídas, renovadas, disseminadas, por vezes inventadas, e por muitas utilizadas para questionar e mostrar o presente nacional, ou para suportá-lo diante de uma situação de crise. No entanto, para entrarmos nessa pesquisa e discussão de maneira responsável, uma tese de doutorado talvez fosse insuficiente - e decerto já existe um tal estudo. É precisamente uma inquietação na imagem de Camões criada no poema de Sophia o que movimenta a leitura aqui proposta - e desta inquietação outras provavelmente surgirão. Por que teria escolhido Sophia Andresen, no século XX, o pagamento em dinheiro como sinal da humilhação do grande poeta da nação, de maneira tão próxima à noção de um Camões miserável e pedinte como a que circulou no século XIX? Mas talvez dentro dessa pergunta existam duas ou mais.

Quando n'Os Lusíadas, na notável oitava de número 145 do Canto $\mathrm{X}$, em uma sensível soma de indignação, cansaço e desilusão, o poeta abdica do próprio ato de cantar, dirigindo-se ao então rei D. Sebastião, por já reconhecer sua voz como impotente diante do estado de cobiça, da busca desenfreada de lucro que toma conta da pátria portuguesa, já surge levantada a questão do dinheiro diante da literatura. Duas noções fundamentais de valor são ali colocadas, porém em conflito e cisão, a cultura e o dinheiro. Se tais versos reconhecidamente lamentam e criticam, por um lado, a surdez, o endurecimento, a ignorância, o baixo nível de instrução e ilustração do povo para o qual deveriam estar direcionados, por outro, 
atribuem a deplorável condição cultural à ambição generalizada que assola a coletividade. Camões, reconhecidamente, constrói não só uma crítica pungente à sociedade portuguesa dos fins do século XVI, como, de maneira paralela, assume uma reflexão das mais lúcidas acerca do papel e da (des)valorização da literatura dentro daquela.

No mais, Musa, no mais, que a Lira tenho

Destemperada e a voz enrouquecida,

E não do canto, mas de ver que venho

Cantar a gente surda e endurecida.

O favor com que mais se acende o engenho

Não no dá a pátria, não, que está metida

No gosto da cobiça e na rudeza

Dhia austera, apagada e vil tristeza. (X, 145)

Não há nesse ponto qualquer indício de paciência ou resignação, nem de humilhação ou mendicância. Estão ali, sim, o canto e a erudição, de um lado, o dinheiro e a cobiça, de outro, como direções e escolhas excludentes entre si. Ele distingue e ergue, sutil e consequentemente, a noção de uma recompensa, "O favor com que mais se acende o engenho", que não o dinheiro, que não a riqueza, pois que desses se ocupa a ambição; divisa uma recompensa que a pátria de então não lhe dá, já que está preocupada em lucrar, nem lhe dá a sua gente, posto que endureceu e é surda. Os versos carregam, acima de tudo, a sugestão de anterior esperança em um povo capaz de ouvir e compreender a grandeza do canto de sua própria fundação, expectativa ali já dilacerada mas que, em contrapartida, aponta o seu abstrato dedo diretamente ao valor que para o poeta é a verdadeira e única recompensa ao seu ofício e à sua existência, a justa recepção.

O verso de Sophia "Pois não te pedem canto mas paciência" é o que mais se aproxima da precária recepção apontada pelo texto de Camões, de quem o canto não pedem mas a paciência - que nesses versos do Canto $\mathrm{X}$, foi claramente perdida. Podemos entender, ainda, a partir do valor dado pelas palavras de Camões à leitura e ao entendimento da obra, numa primeira aproximação, que o poema andreseniano veja na pensão - a recompensa em dinheiro por algo que não tem preço - uma forma de humilhação. Obviamente isto suscitaria inquietações maiores e sem respostas, pois todo o mecenato desde a Antiguidade e até mesmo todo o preço pago hoje pela arte seriam, então, entendidos como uma forma de tratamento vexatório ao artista. Estaríamos hoje em dia ofendendo um pintor ao comprarlhe um quadro ou apenas quando a quantia paga fosse escassa? Quanto ao Camões dos versos andresenianos, estaria assim sua humilhação contida na imagem de ir buscar uma espécie de quantia limitada e não uma grande riqueza? Por esse caminho, poderíamos até mesmo pensar que a aproximação com o ato de ir receber um salário ou uma aposentadoria seria em si mesmo algo comparável a uma ação vergonhosa, pois exige que uma pessoa vá buscá-lo todo mês em troca de seu tempo e esforço. Mas uma reflexão por esses caminhos não daria conta do que deve ser observado em "Camões e a tença”, do que está de fato em questão ali, que talvez não esteja na noção da tença como pensão em dinheiro ou na sua quantia.

Se o valor esperado por Camões, no trecho citado d'Os Lusíadas, não parece ser exatamente contável em numerário, torna-se um tanto intrigante pensarmos nas leituras posteriores que adotaram a sua pobreza material como indício da grande ingratidão pátria, quando a pobreza de instrução e de recepção da 
coletividade é que foram cantadas por ele como a miséria maior. O século XIX disseminou essa imagem da ingratidão representada na pobreza, belamente, seja com Garrett ou Gomes Leal, cada um ao seu modo, assim como muitos outros, até mesmo em vários países. Entretanto, mesmo não sendo esse o valor mais importante, um poeta tem que comer, beber, vestir-se, habitar, isso não precisava nem ser dito, porque é claro, e nos remete de novo ao problema do dinheiro diante da arte e mesmo do trabalho. Porém, principalmente, Camões é naquelas obras, como já dissemos, e muitos outros disseram anteriormente, sobretudo uma chave para olhar o presente. Também aquele poeta do século XVI olhava para o seu próprio presente quando na oitava de número 93, no Canto IX, alertava para a necessidade de conter a cobiça, a ambição, a tirania, e para um imperativo de justiça na distribuição de honrarias e riquezas, ou em outras palavras, para a importância do merecimento. A sua balança de valores acerca de honras e ouro fica, mais ainda, exposta: "Milhor é merecê-los sem os ter,/ Que possú-los sem os merecer." (IX, 93).

José Carlos Seabra Pereira, em prefácio a uma edição relativamente recente de $A$ fome de Camões, de Gomes Leal, aponta diferenças entre a imagem daquele poeta seiscentista ali construída e a que tinha sido anteriormente apresentada por Garrett em Camões. Este, na primeira metade do século XIX, afirma Seabra Pereira, havia recorrido à "mitificação de Camões como poeta da pátria e da sua ausência", ao passo que Gomes Leal, assinalando o tricentenário da morte do autor d'Os Lusíadas, o constitui como exemplaridade em seu poema, o "arquetípico Génio de que Camões é avatar" (PEREIRA in LEAL, 1999, p. 9).

É precisamente o fato de, ao irmos a Gomes Leal, o poema $A$ fome de Camões parecer tão próximo ao "Camões e a tença" no que diz respeito estritamente à imagem do poeta genial humilhado e quase mendicante, o que motiva a pergunta central desta leitura. Isso, mesmo se, por outro lado, também o Camões de Garrett chegue a convergir com o poeta representativo de uma pátria ausente, que ao ser invocada não acordou, tal como é constituído no poema de Sophia. Mas é a noção desse poeta pedinte que sobretudo nos interessa por ora. "Quando no mundo o Génio abandonado/ expira à fome e ao frio, indignamente, (...)" (LEAL, 1999, p. 47), dizem versos do poema de Gomes Leal no século XIX sobre um Camões que chegou a se deitar no lodo da rua. Naquele, a Lira de Camões é tida como plena de ameaças, vinganças, desgraças: "é a Lira terrível da Consciência" (LEAL, 1999, p. 47). No Canto Terceiro do texto, encontraremos a imagem de um velho paupérrimo que entra e interrompe uma luxuosa festa para fazer um pedido bem insólito - ou talvez bem concreto - como esmola:

E o velho disse: - "Estranho é meu pedido!

Estranho sim! No meio duma festa: mas venho por um morto protegido, e este pedido os lábios não me cresta! Para um Génio de que hoje nada resta, para um Génio da fome consumido, um Génio infeliz! um apagado sol, venho pedir a esmola dum lençol!” (LEAL, 1999, p. 77)

Mas, no poema "Camões e a tença", a ação de ir pedir a pensão junto ao paço está expressa em um tempo verbal que a situa no futuro do presente: "Irás ao Paço. (...)” (ANDRESEN, 2003, p. 72). Os tempos verbais, que em geral não 
são muito observados nas leituras sobre a obra de Sophia, são, contudo, uma clave fundamental de seu entendimento, pois muitas vezes indicam a incompletude, o não-cumprimento, a aspiração de algo que ainda não aconteceu. Fátima Freitas Morna, em uma leitura do poema andreseniano "Meditação do Duque de Gandia sobre a morte de Isabel de Portugal", aponta que "o futuro acenado no tempo verbal ('será', 'poderá) é teia desfeita, passos perdidos num não-tempo infinito e eterno: 'Nunca mais'." (MORNA, 2004, p. 12). Tal entendimento pode fornecer aberturas para a compreensão também do tempo em "Camões e a tença", que, por sua vez, não decorre relegado a um "Nunca mais", como naquele poema inclúido em Mar novo (Cf. ANRESEN, 2005, p. 28), mas, de maneira semelhante, é aprisionado em um presente interminável e um futuro inacessível. Irás ao Paço, ainda: ou a ação ainda não decorreu, ou se recria uma ideia de maldição ou sentença, divina ou do destino. Podemos observar os outros tempos que surgem no poema e vêm expor melhor a imagem de Camões:
Irás ao Paço. Irás pedir que a tença
Seja paga na data combinada
Este país te mata lentamente
País que tu chamaste e não responde
País que tu nomeias e não nasce (ANDRESEN, 2004,
p. 72)

A partir dessa estrofe inicial composta por cinco versos, é importante notarmos, de antemão, que o poema definha, afina-se em número de versos a cada estrofe, também morre lentamente. As cinco estrofes de que é formado têm a composição de versos em 5, 4, 4, 2, 1, uma debilitação gradual, mas desigual. Além disso, é relevante o verso "Este país te mata lentamente", repetido ainda ao fim do poema, de maneira isolada, como fechamento. Após verbos no futuro, um verbo matar situado no tempo presente do modo indicativo aponta, sem dúvida, uma ação nacional que é contínua, constante, cruel, atual: lentamente. Daí podemos supor que decorre ainda, o que imediatamente joga a forma irás para a frente na linha temporal, ou melhor, a projeta para um futuro, naquele movimento aqui citado, permanente, entre presente e futuro.

Na mesma estrofe, a imagem do "País que tu chamaste" encena uma ação no pretérito perfeito, passada, que remete à desistência do poeta no Canto X d'Os Lusiadas diante da gente surda e endurecida, como dizem as palavras de Camões, ou gente que não responde, como dizem as de Sophia. Notemos que o "País que tu nomeias e não nasce" é um verso absolutamente no presente (ANDRESEN, 2004, p. 72). Se a ação de chamar está no passado, o tempo de uma resposta que não chega é um presente imenso e sem limites. Nesse ponto, é Camões a imagem do falhanço, e mais, da falha de um projeto poético que é também o da própria Sophia, o da nomeação do mundo, de concreção, ou do dar a ver pelo nome, no caso, ao país.

Podemos incluir nessa reflexão que o presente em que "nomeias e não nasce", o presente de Dual, é 1972, é também a década anterior, de 60, a guerra colonial, o salazarismo, a censura, o isolamento português dentro de um mito de grandiosidade nacional e também, não devemos esquecer, a utilização da imagem de Camões como prova de que Portugal se basta, mesmo se isolado. Inevitavelmente voltamos à leitura andreseniana que envolve a política e o contexto do seu tempo de enunciação. Mas, além disso, os versos de Sophia olham também para um século XVI de calúnias, inveja, conluios - este para utilizarmos um termo 
que aparecerá anos depois na "Lisboa" de Naregaçoees. Essa atmosfera de falsidades e traições, acrescida da impotência do canto, surge nas duas estrofes seguintes, ambas compostas por quatro versos.

Em tua perdição se conjuraram

Calúnias desamor inveja ardente

E sempre os inimigos sobejaram

A quem ousou seu ser inteiramente

E aqueles que invocaste não te viram

Porque estavam curvados e dobrados

Pela paciência cuja mão de cinza

Tinha apagado os olhos no seu rosto (ANDRESEN, 2004, p. 72)

É perceptível que os versos de Sophia Andresen transformam o discurso lírico camoniano de "Erros meus, má fortuna, amor ardente", relação sobre a qual vale a pena apontar que o texto de Sophia desloca os erros e enganos pessoais que apareciam naqueles versos do século XVI para erros e enganos causados por outros. É nesse ponto que se torna importante trazermos também o poema de Jorge de Sena intitulado "Camões dirige-se aos seus contemporâneos", datado de 1961, muito próximo, menos de uma década, portanto, da publicação do volume Dual em que "Camões e a tença" se insere. "Podereis roubar-me tudo:/ as ideias, as palavras, as imagens", começa o texto seniano a dirigir-se de maneira mordaz a tais contemporâneos. Os versos de Sena enumeram e criticam causticamente as atitudes de um tempo que remontam pleno de inveja, plágio, roubo, traição, além de lançar uma promessa de vingança trazida pela posteridade, pela própria imortalidade da obra - valor principal daquele poema - e, sobretudo, pelo vulto que ganhará, juntamente com a figura de seu autor, a ponto de englobar, absorver para seu universo e sua sombra, todo o entorno: "Nada tereis, mas nada: nem os ossos, / que um vosso esqueleto há-de ser buscado,/ para passar por meu. (...)" (SENA, 1999, p. 100).

O Camões indignado, vociferante e confiante de Sena, contudo, contrasta em quase tudo com o de Sophia, que precisa ser paciente, resignado, e que é marcado pela falha. Seus pontos de convergência encontram-se na imagem de estarem ambos submersos em uma contemporaneidade de enganos, assim como em se constituírem como um desdobramento dos próprios poetas que o compõem, da sensação de fracasso, humilhação e tentativa de paciência de Sophia, e da indignação, revolta e certeza do próprio valor em Sena. Ao criticarem o tempo do enunciado, a época de Camões, constroem uma crítica paralela à sua própria contemporaneidade.

No poema de Sophia, de fato, há a reformulação de um Camões romântico, humilhado, comparável ao pedinte de Gomes Leal, mas partindo da imagem desse poeta aposentado e frustrado, entretanto, de maneira alguma se pode deixar de lado a crítica ao presente de que é acrescida e seu papel de representante, mais uma vez, de uma coletividade em crise. Assim, antes de concluirmos que o poema de Sophia de Mello Breyner Andresen compõe apenas algo semelhante a uma visão neo-romântica da figura de Camões, o que seria obtuso, ainda mais considerando o contexto nacional e político em que "Camões e a tença" veio a público, voltamos ao volume Dual, onde, sem dúvida, está mais uma chave para o complemento da leitura daquele texto poético. O poema está devidamente arranjado em uma parte do livro intitulada "Em memória", a última entre as seis 
partes em que aquele compêndio publicado em 1972 aparece dividido. Na seção encontram-se sete poemas além da "Arte poética IV": "Em memória", "Caxias 68", "A paz sem vencedor e sem vencidos", "Camões e a tença", "Retrato de uma princesa desconhecida", "Catarina Eufémia", "Maria Natália Teotónio Pereira".

Uma leitura atenta dos sete poemas mostra que se utiliza e confirma uma marca extremamente relevante na poesia andreseniana, a influência fundamental da ordem em que os textos estão organizados dentro dos livros no sentido que os mesmos textos passam a carregar, de uma maneira bem próxima ao efeito que a montagem das imagens proporciona, na arte cinematográfica, aos seus sentidos e ao sentido inteiro do filme - conhecido também como efeito K. Sophia Andresen usa esse recurso larga e conscientemente em sua obra. Tal trabalho surge potencializado em alguns trechos de livros da autora, pontos em que está mais perceptível, porém, em geral, é importante em grande parte do conjunto de seus poemas - e talvez até em todos.

No volume Lirro sexto, por exemplo, temos essa ocorrência mais acentuada na sequência em que se encontram dois poemas que carregam em seu início o mesmo sintagma "Nunca choraremos bastante". Intitulados "Pranto pelo Infante D. Pedro das Sete Partidas" e "Pranto pelo dia de hoje", seus sentidos se articulam complexamente e de maneira complementar, o que é intensificado pela ordem em que aparecem, ligando assim diferentes tempos e contextos, completando-se em sentido, seja o tempo do infante, seja o da censura tratada no segundo poema, ou da entrada em Goa dos soldados indianos, como diz um parêntese que interrompe o primeiro poema e o data de 17-12-1961 (ANDRESEN, 2003, p. 58-59). Tal parêntese, por sua vez, produz o efeito de uma verdadeira âncora sobre o pacto de veracidade com o leitor, ao cravar o poema diretamente no contexto histórico nacional, dotando - e datando - o texto poético de um sentido documental em si, mesmo que ficcionalizado. Trata-se de um recurso bastante utilizado nos romances de metaficção historiográfica do período pós-colonial, em que a inclusão de documentos históricos e a sua ficcionalização se tornaram indistintos - como expõem estudos de Maria Lucia Lepecki e outros textos que se ocupam do assunto (Cf. Lepecki, 1984). Sophia utiliza-se do recurso à ficcionalização do fato histórico e historicização da ficção em alguns pontos específicos de sua obra, já antes do 25 de Abril.

De volta a Dual, à parte "Em memória" e à sequência de textos que comporta, percebemos que é aberta por um curto poema que ao propor uma releitura de um verso de "O menino da sua mãe", de Fernando Pessoa, apresenta uma crítica ao próprio contexto dos conflitos pela defesa do poder sobre Goa, conforme explicita o primeiro verso: "Por Goa sacrificado". Os últimos dois, que trabalham diretamente na leitura do discurso de Pessoa, apontam que são as "Malhas que o império tece/ Mesmo depois de perdido" (ANDRESEN, 2004, p. 69). Por extensão, é possível inclusive ler esse texto como uma referência, sutilizada, aos conflitos chamados de guerra colonial e, ainda, a toda a política colonialista do governo português de então.

O texto seguinte, nessa mesma parte de Dual, intitula-se "Caxias 68". Dentro daquele grau de apagamento de referências próprio dessa poesia - o que torna sua crítica política tantas vezes questionada e apenas algumas vezes realmente questionável - traz as imagens de muros, portões, chaves, luz recortada, grades. Fica sugerida, dessa maneira, a figura total de uma prisão, ou melhor, de uma visita a alguém que se encontra preso, sendo um poema que, ao aparecer datado de "Fevereiro de 1968", ganha uma força expressiva incrível na crítica ao contexto 
político, retomando o efeito mencionado: "O meu amor por ti é fundo e grave/ Confirmado nas grades deste dia” (ANDRESEN, 2004, p. 70).

O terceiro poema da parte intitulada "Em memória" é "A paz sem vencedor e sem vencidos" e vem na mesma direção do anterior, mas com um forte fundo religioso: "Fazei Senhor que a paz seja de todos", diz um dos versos (ANDRESEN, 2004, p. 71). Os poemas seguintes já são "Camões e a tença" seguido de "Retrato de uma princesa desconhecida". Deste último é importante repararmos em uns versos:

Para que a sua espinha fosse tão direita

E ela usasse a cabeça tão erguida

Com uma tão simples claridade sobre a testa

Foram necessárias sucessivas gerações de escravos

De corpo dobrado e grossas mãos pacientes

Servindo sucessivas gerações de príncipes (ANDRESEN, 2004, p. 73)

Em relação a esses escravos de corpo dobrado e mãos pacientes, encontramos em "Camões e a tença" uma imagem muito semelhante, daqueles que estavam currados e dobrados pela paciência. Se "Retrato de uma princesa desconhecida" constrói uma espécie de crítica de classes - porém uma que de maneira um pouco ambivalente se aproxima de uma visão determinista -, podemos supor que a utilização tão semelhante no poema imediatamente anterior tenha o efeito de tornar a este um tanto ancorado também nesse tipo de crítica. Eis o resultado, novamente, do efeito K. Esse é um ponto importante: "E aqueles que invocaste não te viram/ Porque estavam curvados e dobrados" (ANDRESEN, 2004, p.72). Agora, no entanto, perguntemo-nos quem são exatamente aqueles que invocaste. É possível perceber de duas maneiras o verso. Uma que aponta estarem todos os portugueses dobrados, subjugados, se entendermos que Camões invocava toda a população da pátria. A outra transfere a este a divisão em classes do texto poético seguinte e, assim, expõe que uma parte dos portugueses que o autor d'Os Lusíadas invocava não o pôde ouvir pois estava, na prática, escravizada. É, no entanto, uma ambiguidade sem solução.

O poema seguinte a "Retrato de uma princesa desconhecida", na mesma parte de Dual, com o título de "Catarina Eufémia", é provavelmente o mais politicamente posicionado de toda a obra poética de Sophia de Mello Breyner. Catarina Eufémia foi, de fato, uma camponesa assassinada em 19 de maio de 1954, com o filho mais novo ao colo, pelas forças policiais do regime, tornandose então grande ícone da resistência do proletariado rural alentejano. Há diferentes versões de sua morte, algumas - de jornais de esquerda - contam que estava grávida, e esta é uma imagem utilizada no poema de Sophia: "Estavas grávida porém não recuaste" (ANDRESEN, 2004, p. 74). Tal poema tem muitos meandros, recorrendo desde à tragédia de Antígona e aos conceitos de justiça humana e divina para um corpo que não teria sido enterrado, até às reportagens de jornais de esquerda de que visivelmente a autora se serviu - e que podem hoje ser encontradas na íntegra em rede. Cabe apontarmos somente que, nos versos, são focados naquela personagem histórica a força, a atitude, o posicionamento como trabalhadora e como mulher: "E não ficaste em casa a cozinhar intrigas" (ANDRESEN, 2004, p. 74). 
O poema seguinte segue o mesmo sentido que o relacionado àquela trabalhadora rural morta pela polícia, mas dessa vez em relação a Maria Natália Teotónio Pereira, outra verdadeira personagem histórica do século XX, de que podemos já dizer que junto ao seu marido teve importante participação na década de 1960 nos projetos desenvolvidos pelos chamados católicos progressistas em Portugal, entre estes a Comissão Nacional de Socorro aos Presos Políticos.

"Camões e a tença" carrega, dessa forma, sobretudo se lido nesse conjunto, assim como o poema seniano "Camões dirige-se aos seus contemporâneos", o olhar crítico ancorado no contexto nacional, refletido através do olhar para o passado. Como o célebre mito de Antígona também se reflete na história da morte de Catarina Eufémia, ainda como as classes dos príncipes e seus escravos são uma crítica às classes dobradas e curvadas de hoje, às relações de trabalho, ou como a história de D. Pedro das Sete Partidas aponta-nos uma tristeza, uma traição, semelhante à que produz a censura, também o destino de um poeta do século XVI parece espelhar a história bem atual do povo português. Essa é ainda a parte mais evidente da leitura do texto poético andreseniano, a de Camões como 'portavoz' do protesto português num período autoritário, um Camões mais uma vez remontado e sacrificado em um tempo de crise, como imagem da ofensa a toda uma nação.

É importante não esquecermos, em meio a tudo isso, que "Camões e a tença" se insere em uma parte de Dual intitulada "Em memória”. Está claramente indicado que há algum morto: o soldado, metaforicamente o provável preso político, a trabalhadora rural, a pessoa que lutou em prol dos presos políticos, as várias gerações de escravos das várias gerações de príncipes e mesmo a paz em equidade. Pensemos então que o verso "Este país te mata lentamente", num movimento contrário de irradiação, mas se utilizando do mesmo efeito de montagem, influencie no sentido dos outros poemas da divisão e que sejam aqueles representantes de crimes - metafóricos ou factuais - ligados a uma ação contínua e nacional: lentamente. O país mata-os, a todos esses, a cada dia.

Vejamos que, sim, está lá um Camões pedinte e representante de uma coletividade, como uma espécie de reedição da visão romântica, mas num olhar atualizado e carregado de questionamentos políticos, a ponto de poder ser mesmo um texto central na irradiação do sentido da parte em que se insere. Entretanto, em um poema intitulado "Camões e a tença", curiosamente, em nenhum momento, em nenhum verso, em nenhuma imagem ou palavra a pensão é tratada como uma quantia, nem como uma quantia escassa, não aparece contada ou contável. Não é mencionada qualquer miséria ou pobreza do poeta que seja por ela causada, o que afasta em parte o Camões ali encenado daquele poeta miserável como apresentado pelo Gomes Leal, apesar da sua ação em algum grau semelhante, de irpedir. Nesse ponto, a tença precisa ser lida como outro tipo de valor, não contável, o que mostra que provavelmente não está no pagamento a noção de humilhação.

"Irás ao Paço. Irás pedir que a tença/ Seja paga na data combinada" são os versos em que começamos esta leitura (ANDRESEN, 2004, p. 72). De maneira aparentemente paradoxal, em todo o texto poético em que se encontram, e que abrem, são a única menção à tença, seguida então de alusões a perdição, calúnias, desamor, inveja, ignorâncias, impotência, incomunicabilidade e todo um conjunto de desenganos que cercam a figura de Camões ao longo do poema. Duas preocupações orbitam a imagem da pensão aí apresentada, a da vexatória e paciente ação de ter que ir pedir, que já foi aqui observada, e a de que seja paga na data combinada. Em um poema chamado "Camões e a tença", a preocupação maior em torno de seu pagamento ser a data é algo que precisa e deve chamar muito a 
atenção. Sobretudo se o poema tem o seu tempo de ação preso entre um presente interminável em que se recolhem as falhas e um futuro sempre projetado para a frente.

Está, assim, no tempo do poema, o grande entendimento da afronta àquele que é tido como representante de um país, na infinita paga de "insulto e morte" recebida por ele de modo semelhante ao Infante D. Pedro das Sete Partidas construído por Sophia, na paga deixada por abundantes inimigos que "conjuraram" e "sobejaram", ou de homens que "não te viram". Notemos que as últimas são ações verbais passadas e conclusas, no pretérito perfeito e sintetizam a origem de um pagamento e um valor que Camões colhe ininterruptamente num presente infindável: "Este país te mata lentamente", "não responde". Mas, principalmente, está em outro pagamento, outro valor, a tença que ele irá pacientemente reivindicar junto ao governo, junto a um palácio real, num tempo futuro ainda intangível, inalcançável, mas que uma data que fosse, uma data combinada que fosse cumprida, seria capaz de tornar realidade palpável e recompensa, ou melhor, de tornar uma tença que é de insulto e morte numa tença de valorização, de entendimento, de justa recepção do canto. 


\section{REFERÊNCIAS BIBLIOGRÁFICAS}

ANDRESEN, Sophia de Mello Breyner. Liuro sexto. Ed. definitiva. Lisboa:

Caminho, 2003.

Dual. Ed. definitiva. Lisboa: Caminho, 2004.

. Mar noro. $4^{\mathrm{a}}$ ed., revista. Lisboa: Caminho, 2005.

CAMÕES, Luís de. Os Lusíadas. Edição de Emanuel Paulo Ramos. Porto: Porto Editora, 2003.

LEAL, Gomes. A fome de Camões. Ed. e introdução, J. C. Seabra Pereira; ed. 542. Lisboa: Assírio \& Alvim, 1999.

LEPECKI, Maria Lúcia. O romance português contemporâneo na busca da história e da historicidade. Paris: Centro Cultural Português, Fundação Calouste Gulbenkian, 1984.

MORNA, Fátima Freitas. Senhores que podem morrer. In: CONSELHO DIRETIVO E CIENTÍFICO DA FLUP (org.). Estudos em Homenagem a Sophia de Mello Breyner Andresen. Porto: FLUP, 2005.

PEREIRA, J. C. Seabra. Introdução a LEAL, Gomes. A fome de Camões. ed. 542. Lisboa: Assírio \& Alvim, 1999.

SENA, Jorge de. Antologia poética. Edição Jorge Fazenda Lourenço. Porto: Asa, 1999. 